\title{
Variation of Net Radiation and Solar Spectrum in Thailand
}

\author{
Pannop Limhoon and Surat Bualert
}

\begin{abstract}
Variation of Net radiation and Solar spectrum in Thailand determine the Net radiation and Solar spectrum to compare the environment. The preparation databases amount of solar radiation to be aware change types quantity proportion and distribution of the ratio change each area can influence change the net radiation and spectrum of solar radiation that is received. Measuring and monitoring solar radiation at the wave length 350-1050 $\mathrm{nm}$ since November 2010 - February 2011 and March 2011 - March 2012 by instrument netradiometer, CNR4 and Spectroradiometer (EKO, MS-700). The results showed that net radiation was lowest in rainy season. In rainy season was highest decreasing percentage compared to summer. Seasonal variation of the averaged radiation at the wavelength range $351-1050 \mathrm{~nm}$ showed a good agreement to net radiation, highest in summer rain and winter respectively. In the rainy season, massive cloud, and humidity in the air could absorb net radiation causes the net radiation decreasing at the wavelength range 700-1050 $\mathrm{nm}$ of the rainy season, more than other seasons. At the wavelength range $351-700 \mathrm{~nm}$, the net radiation decreasing in the winter caused by the station's location and wind direction which brought particles from the sea. Especially on sea salt affected the net radiation at the wave length range 351-700 nm. It showed a good agreement to [7] [10] which reported that in winter, $\%$ decrease was greater than any other seasons.
\end{abstract}

Index Terms-Seasonal variation, diurnal variation, net radiation, short-wave, solar radiation, particle concentration.

\section{INTRODUCTION}

Sun the most important energy source to the earth. Warming caused by short-wave, but because in many contaminants. So, this short wave radiation is reflected back into the atmosphere before the world or surface adsorption. Therefore, the amount of short wave Earth surface into smaller ones. The process that causes the light reflected in the atmosphere occurs due to a molecule of the substance in the air is much smaller than the radius of the optical wave length. Called a "scattering", this process occurs every direction so that the surface world into short wave and, therefore, caused by the Sun and the scattering by molecules of the substance are sometimes called "sky radiation". Short waves energy reached ground or surface is direct short wave radiation. Some part of them may reflect to the atmosphere is a reflection of the short-wave [1]. The world's surface when it is hot, both short and long waves. The surface world would release radiation into the atmosphere in the form of a long wave terrestrial radiation.

The net radiation was a balance between incoming and

Manuscript received November 11, 2012; revised January 20, 2013.

The authors are with the Environmental Science Department, Faculty Science, Kasetsart University, 50 Namwongvan Rd, Chatuchak Bangkok 10900, Thailand (e-mail: topteam0@gmail.com, surat.b@ku.ac.th). outgoing radiation.

\section{MAterial AND MethoD}

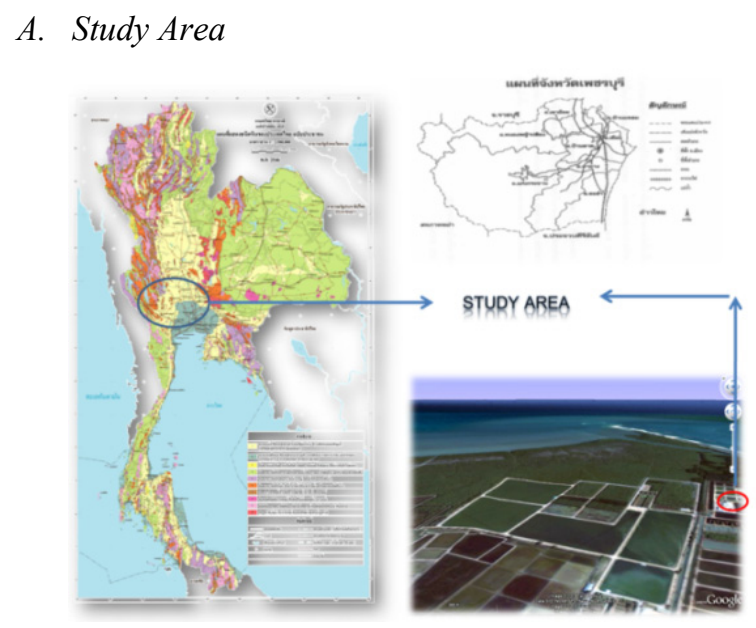

Fig. 1. Study area

The experiment was conducted at the experimental site of The King's Royally Initiated LeamPhakBia Environmental Research and Developmental Project (the Royal LERD-project) at Phetchaburi Province, Thailand.

\section{B. Field Experimental}

Netradiometer, CNR4 was used for measuring net radiation, incoming and outgoing shot wave and long wave. Spectroradiometer (EKO, MS-700) was used for measuring and monitoring solar radiation at the wave length 350-1050 nm since November 2010 - February 2011 and March 2011 March 2012.

\section{Result AND Discussion}

\section{A. Net Radiation}

The net radiation received at the Earth station project at Laem phak bia found that cosmic The highest net radiation received during the winter (November 2010 - February 2011) was 215.1 Watt per square meter during summer (July 2010 - August 2011) was 173.2 Watt per square meter. However, the maximum net radiation was in the summers 856.2 Watt per square meter. Considering the frequency of the radiation quantity was higher than 700 Watt per square meter. During the summer, the maximum frequency was 5.2 percent of all information. The summer and winter there were 1.7 and 3 percent of the total, respectively.

Analyzing the ratio between short wave radiation reflected from the Earth (Rsu) and incoming short wave solar radiation (Rsd) or reflection Ray (Albedo) found that the short-wave 
radiation reflected in the summer rainy and winter were between $0.12-0.170 .120 .18-0.12-0.17$, respectively, and mean 0.136 by reflection radiation values found in the range is less than the summer season and winter.

\section{B. Spectral of Incoming Solar Energy}

February 2011. Because the distance between the noon sun with the world is the distance that is closer to the maximum. Adsorption and scattering in around a day. As a result, the departure of Ray. Variation of radiation characteristics of wavelength 300 to 1140 nanometer. I found that there were significant energy absorption at wave length 930940760 720 and 810820950 nanometer due to moisture and humidity in the atmosphere.

\section{Spectral of Outgoing Radiation}

During November 2010 - February 2011, the highest outgoing of radiation was 198 Watt per square meter per nanometer at $11.00 \mathrm{a} . \mathrm{m}$. at the wavelength of 770-780 nanometer due to the angle of the Sun to the Earth is smaller and is not equal to zero. In the night time, the earth does not receive sunlight. Influence of ground heat (re-radiation as a long wave radiation) increase the energy at longer wavelength (1080 nanometer).

\section{Diurnal Variation of Net Radiation}

Net radiometer showed diurnal variation and seasonal variation of solar energy of Thailand, summer (March-May), rainy (June-October), winter (November-February).

Averaged net radiation in summer show the highest energy $\left(672.68 \mathrm{~W} / \mathrm{m}^{2}\right)$ at $12.00 \mathrm{am}$ as same as rainy $\left(629.24 \mathrm{~W} / \mathrm{m}^{2}\right)$ and winter season $\left(665.08 \mathrm{~W} / \mathrm{m}^{2}\right)$ (Fig. 2 and Table I).

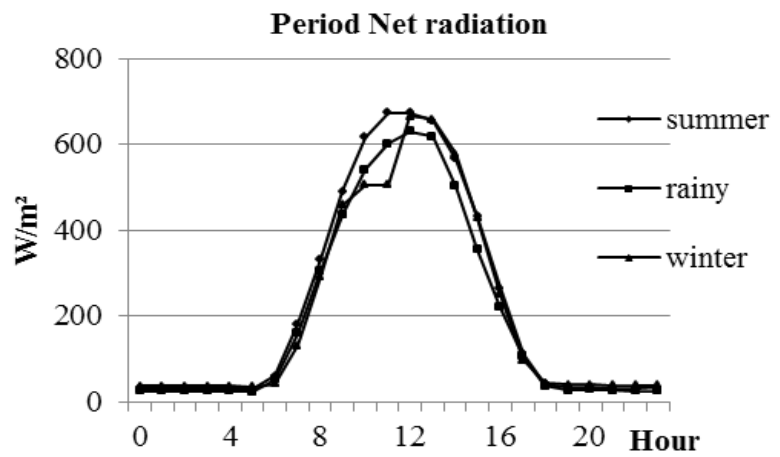

Fig. 2. Net radiation since March 2011 - March 2012.

Fig. 2 showed that net radiation in rainy season was lower than summer and winter especially at 9.00-11.00am, net radiation was lowest due to the sun angle at winter time. The energy lost in the winter because Earth orbit away from the Sun than summer time. That causes solar radiation travel more far away. The solar radiation passé through the air and easy to scat especially on the short wave radiation such as ultraviolet (UV). Furthermore, in the morning the sun angle is perpendicular to the Earth.

Seasonal comparison showed that summer net radiation was decreased. In the winter time, sunshine duration was shorter than summer but the net radiation was higher that summer and rain season (Fig. 3) which was lower net radiation due to rainy cloud.
TABLE I: DIURNAL AND SEASONAL VARIATION OF NET RADIATION IN THAILAND (MARCH 2011-MARCH2012)

\begin{tabular}{|c|c|c|c|}
\hline & summer & rainy & winter \\
\hline 0 & 31.660802 & 24.58588 & 37.00404 \\
\hline 1 & 30.876944 & 24.34862 & 36.19126 \\
\hline 2 & 30.064729 & 24.51848 & 36.48737 \\
\hline 3 & 29.994356 & 23.9909 & 35.89747 \\
\hline 4 & 29.257221 & 24.53729 & 35.45195 \\
\hline 5 & 29.392785 & 23.19034 & 35.13339 \\
\hline 6 & 59.183704 & 50.78309 & 40.59572 \\
\hline 7 & 180.02932 & 158.3263 & 129.6723 \\
\hline 8 & 331.99239 & 304.5982 & 290.8405 \\
\hline 9 & 490.15838 & 434.9566 & 457.6439 \\
\hline 10 & 616.01807 & 540.5965 & 505.2063 \\
\hline 11 & 672.88338 & 600.2261 & 505.3279 \\
\hline 12 & 672.86117 & 629.2448 & 665.076 \\
\hline 13 & 654.86847 & 617.9215 & 657.306 \\
\hline 14 & 565.73807 & 502.5711 & 576.8558 \\
\hline 15 & 431.3262 & 354.3477 & 428.5373 \\
\hline 16 & 265.30518 & 219.5522 & 249.8194 \\
\hline 17 & 112.49498 & 104.3283 & 96.61075 \\
\hline 18 & 41.098409 & 35.35752 & 43.61779 \\
\hline 19 & 33.782855 & 26.41272 & 40.10867 \\
\hline 20 & 32.414715 & 27.03879 & 38.94094 \\
\hline 21 & 31.789976 & 26.24463 & 38.0888 \\
\hline 22 & 31.953966 & 25.17542 & 38.50981 \\
\hline 23 & 32.294115 & 24.72264 & 38.14346 \\
\hline
\end{tabular}

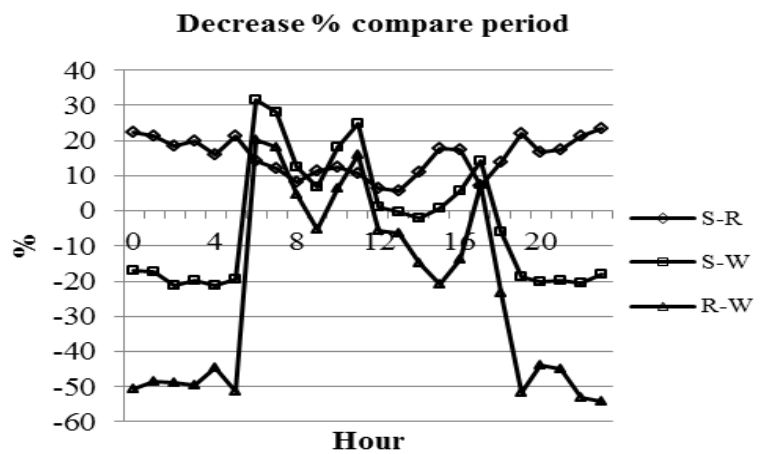

$\mathrm{S}-\mathrm{R}=\%$ decreasing of net radiation in rainy season compared to summer $\mathrm{S}-\mathrm{W}=\%$ decreasing of net radiation in winter season compared to summer $\mathrm{R}-\mathrm{W}=\%$ decreasing of net radiation in winter compared to rainy season

Fig. 3. Decreasing percentage (\%) of net radiation in winter and rainy season compared to summer time .

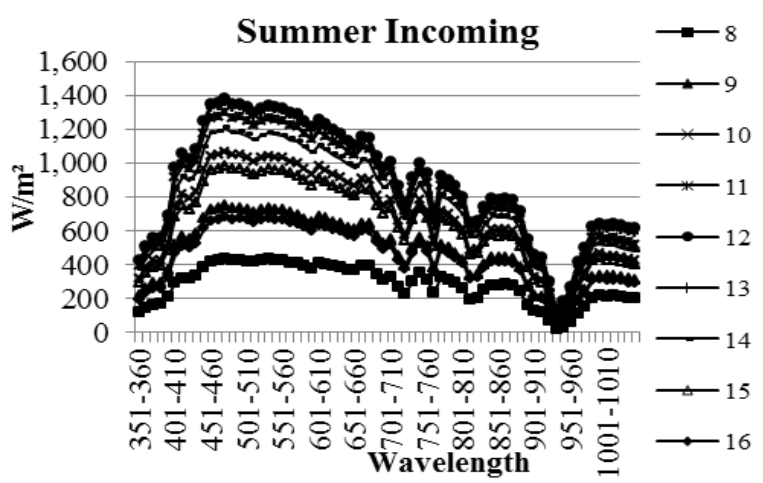



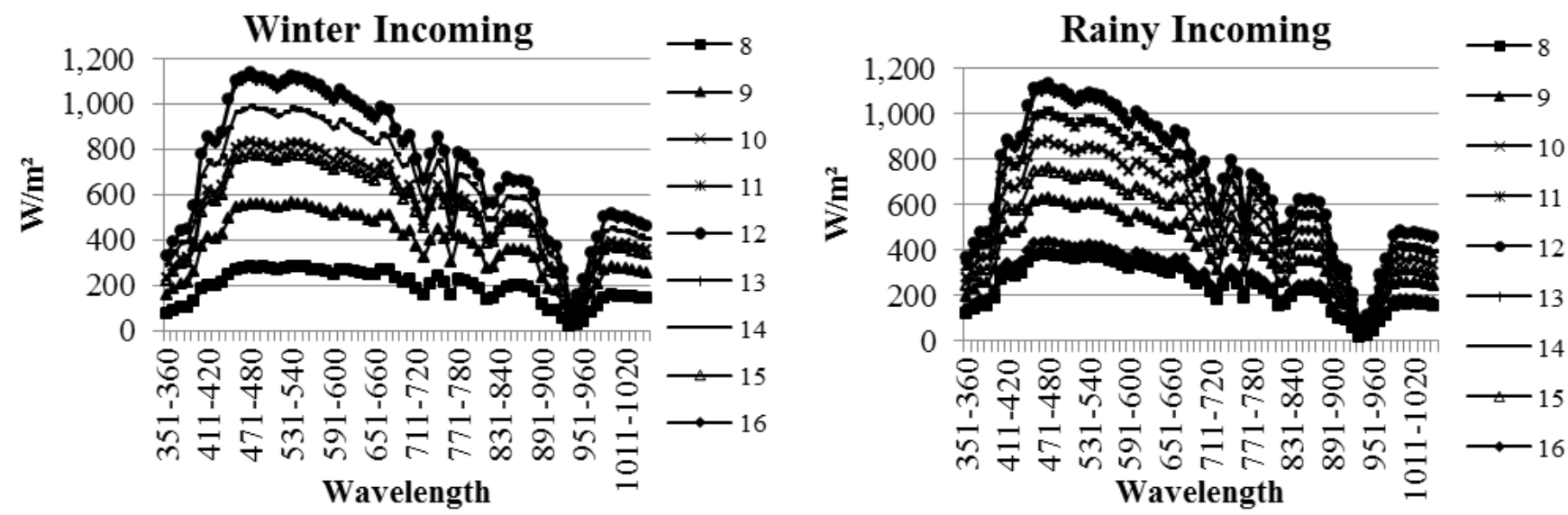

Fig. 4. Incoming solar radiation spectrum (wavelength 351-1050 nm) in summer season during March 2011-March2012

\section{S-R Incoming}

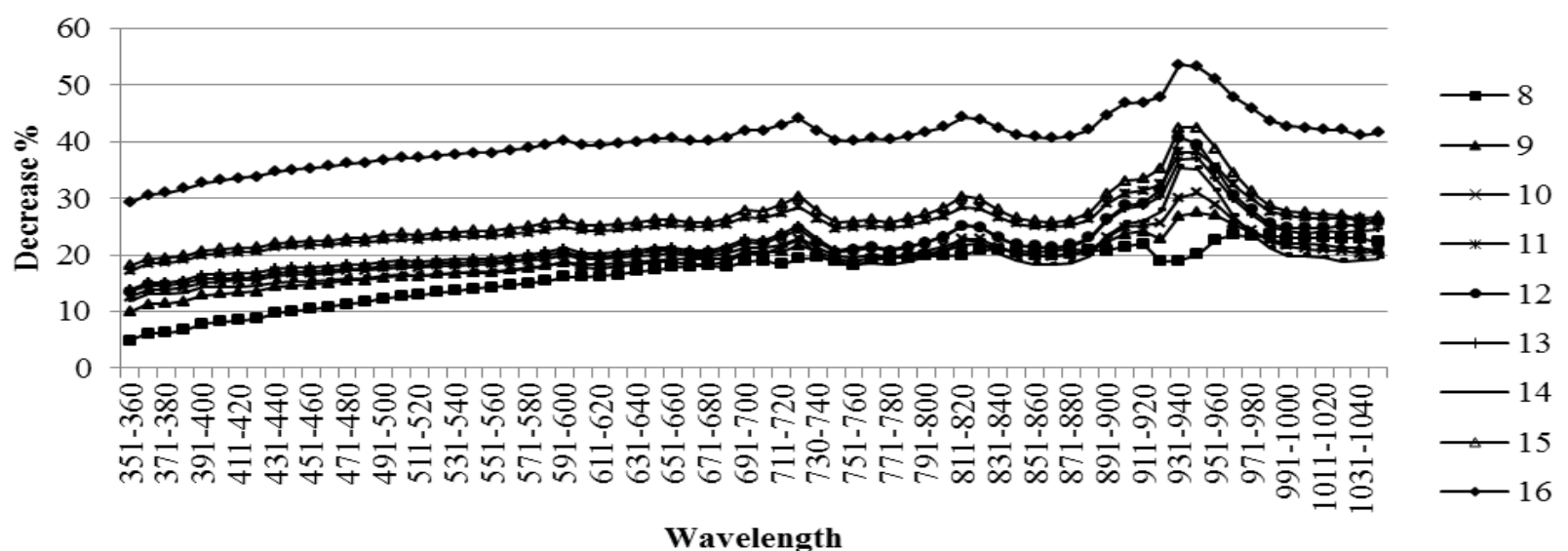

Fig. 5. Decreasing percentage (\%) of solar spectrum (wavelength 351-1050 nm) in rainy season compare to summer time during March 2011-March2012

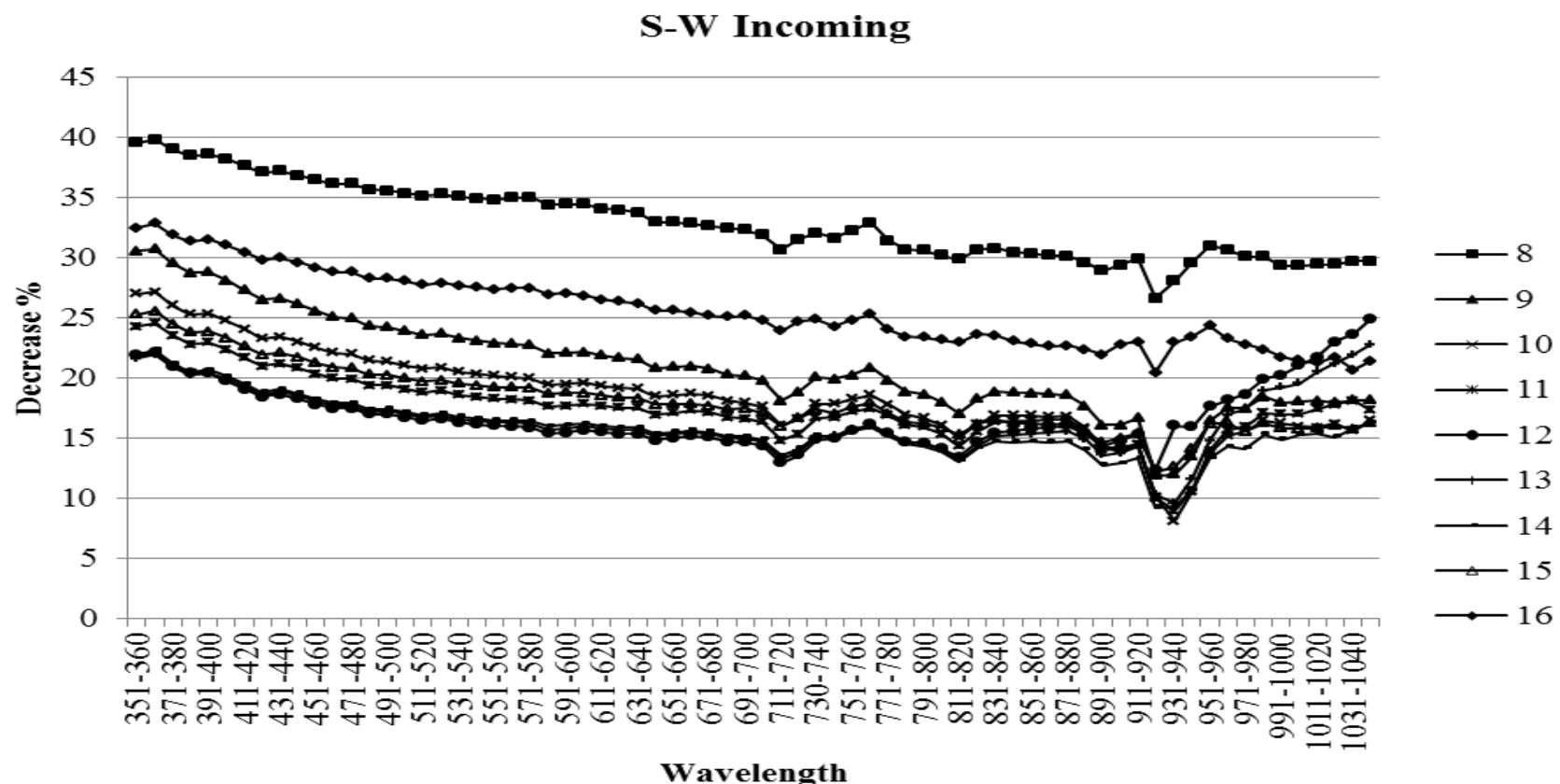

Fig. 6. Decreasing percentage (\%) of solar spectrum (wavelength 351-1050 nm) in winter season compare to summer time during March 2011-March2012

The result showed that summers in Thailand was the highest net radiation among three seasons. The seasonal variation of net radiation showed in the Fig. 4. It agrees with [2]-[10] which reported that the environment was the major factor in summer and winter.
Comparison of decreasing percentage during the rainy season and the summer at the wavelength range $700-1050 \mathrm{~nm}$ radiation. In the daytime, the light is more than $75 \%$ decrease in winter compared to the summer, but at the wavelength range 351-700, winter compared to the summer with more 
than $75 \%$ decrease in comparison with the summer rainy season (Fig. 5 and Fig. 6).

TABLE II: DECREASING PERCENTAGE OF NET RADIATION IN RAINY AND WINTER SEASON COMPARED TO SUMMER

\begin{tabular}{rccc}
\hline & S-R & S-W & R-W \\
\hline 0 & 22.34599 & -16.8765 & -50.5093 \\
1 & 21.14303 & -17.2113 & -48.6378 \\
2 & 18.44771 & -21.3627 & -48.8158 \\
3 & 20.01527 & -19.6808 & -49.6295 \\
4 & 16.13252 & -21.1733 & -44.4819 \\
5 & 21.10193 & -19.5307 & -51.5001 \\
6 & 14.19413 & 31.40727 & 20.06056 \\
7 & 12.05526 & 27.97157 & 18.09809 \\
8 & 8.251447 & 12.39543 & 4.516674 \\
9 & 11.26204 & 6.633466 & -5.216 \\
10 & 12.24341 & 17.9884 & 6.546506 \\
11 & 10.79791 & 24.90111 & 15.8104 \\
12 & 6.482226 & 1.15702 & -5.69433 \\
13 & 5.641889 & -0.37221 & -6.3737 \\
14 & 11.16541 & -1.96518 & -14.7809 \\
15 & 17.84694 & 0.646591 & -20.937 \\
16 & 17.24541 & 5.836983 & -13.7859 \\
17 & 7.259593 & 14.11994 & 7.39737 \\
18 & 13.96865 & -6.13011 & -23.3621 \\
19 & 21.81621 & -18.7249 & -51.8536 \\
20 & 16.58483 & -20.1335 & -44.0188 \\
21 & 17.44369 & -19.8139 & -45.1299 \\
22 & 21.21348 & -20.5165 & -52.9659 \\
23 & 23.44539 & -18.1127 & -54.2856 \\
\hline & & &
\end{tabular}

In the rainy season, it may be caused by a massive cloud, and humidity in the air, it makes those absorption net radiation [4] - [9], [11] caused the net radiation decreasing at the wavelength range $700-1050 \mathrm{~nm}$ of the rainy season, more than other seasons. At the wavelength range $351-700 \mathrm{~nm}$, the net radiation decreasing in the winter caused by the station's location and wind direction which brought particles from the sea. Especially on sea salt affected the net radiation at the wave length range 351-700 $\mathrm{nm}$. It showed a good agreement to [7], [10] which reported that in winter, \% decrease was greater than any other seasons.

\section{CONCLUSION}

Net radiation was lowest in rainy season. In winter especially at $9.00-11.00 \mathrm{am}$, net radiation was lowest due to solar angle in the winter. Furthermore, rainy season was highest decreasing percentage compared to summer. It was difference from winter (night time). The decreasing percentage was increase in the summer. Seasonal variation of the averaged radiation at the wavelength range 351-1050nm showed a good agreement to net radiation, highest in summer rain and winter respectively. In the rainy season, massive cloud, and humidity in the air could absorb net radiation causes the net radiation decreasing at the wavelength range $700-1050 \mathrm{~nm}$ of the rainy season, more than other seasons. At the wavelength range $351-700 \mathrm{~nm}$, the net radiation decreasing in the winter caused by the station's location and wind direction which brought particles from the sea. Especially on sea salt affected the net radiation at the wave length range 351-700 $\mathrm{nm}$. It showed a good agreement to [7], [10] which reported that in winter, \% decrease was greater than any other seasons.

\section{ACKNOWLEDGMENT}

The research is financed by the King's Royally Initiated Leam Phak Bia Environmental Research and Developmental Project.

\section{REFERENCES}

[1] K. Chankaw, Near Surface Meteorology, Department of Conservation, Faculty of Forestry, Kasetsart University, Bangkok, 1979.

[2] S. X. Chu and L. H. Liu, "Analysis of terrestrial solar radiation energy," Solar Energy, vol. 83, pp. 1390-1404, 2009.

[3] C. A. Gueymard, D. Myers, and K. Emery. "Proposed reference irradiance spectra for solar energy system testing," Solar Energy, vol. 73, no. 6, pp. 443-467, 2002.

[4] R. Irshad, R. G. Grainger, D. M. Peters, R. A. McPheat, K. M. Smith, and G. Thomas, "Laboratory measurements of the optical properties ofsea salt aerosol," Atmos Chem Phys, vol. 9, no. 1, pp. 221-230, 2009.

[5] Y. J. I. K. Kaufman, L. A. Remer, D. Rosenfeld, Y. Rudich, "The effect of smoke, dust and pollution aerosol on shallow cloud developmentover the Atlantic Ocean," in Proc. Natl AcadSci, vol. 102, no. 32, pp. 11207-11212, 2005.

[6] A. A. Lacis and J. E. Hansen, Parameterization for the Absorption of Solar Radiation in the Earth'S Atmospheric Science, vol. 31, pp. 118-130, 1974.

[7] N. Manago, S. Miyazawa, Bannu, and H. Kuze, "Seasonal variation of tropospheric aerosol properties by direct and scattered solar radiation spectroscopy," Journal of Quantitative Spectroscopy \& Radiative Transfer, vol. 112, pp. 285-291, 2010.

[8] E. Pettit, "The sun and stellar radiation in astrophysics," J. Hynek ED, pp. 703, New York, McGrawHill, 1951.

[9] T. Takemura, T. Nakajima, O. Dubovik, B. N. Holben, and S. Kinne, "Single-scattering albedo and radiative forcing ofvarious aerosol species with a global three-dimensional model," J. Climate, vol. 15, pp. 333-352, 2002.

[10] Assessment of Solar Energy Balance due to Land Cover Change In Petchaburi Province and Related Areas, The King's Royally Initiated LeamPhakBia Environmental Research and Developmental Project., 2011.

[11] X. Yue and H. Liao, Climatic Responses to the Shortwave and Long-wave Direct Radiative Effects of Sea Salt Aerosol in Present Day and the Last Glacia, 2012.

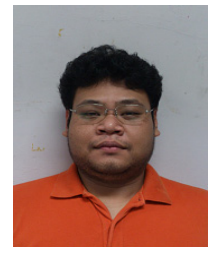

Pannop Limhoon was born on 26 September 1984 in Bangkok. He is now working in the Faculty of Environment, Kasetsart University, 50 Ngam wong wan Rd. Chatuchak, Bangkok, Thailand 10900. He has already got his Ph.D.of Plant Science.

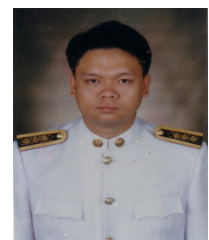

Surat Bualert was born on 8 August 1968 in Bangkok. He is now working as an assistant professor in the Dept of Environmental Science, Faculty of Environment, Kasetsart University, 50 Ngam wong wan Rd. Chatuchak, Bangkok, Thailand 10900. He has already got his Ph.D. of Air Pollution. 